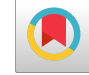

\title{
Phone-Based Interventions to Control Obesity in Children Under Six Years of Age: A Systematic Review on Features and Effects

\author{
Zahra Meidani ${ }^{1,2}$, Ehsan Nabovati ${ }^{1,2,}$, Shirin Gohari ${ }^{2,3}$ and Sara Chopannejad ${ }^{2,3}$ \\ ${ }^{1}$ Health Information Management Research Center, Kashan University of Medical Sciences, Kashan, Iran \\ ${ }^{2}$ Department of Health Information Management \& Technology, School of Allied Health Professions, Kashan University of Medical Sciences, Kashan, Iran \\ ${ }^{3}$ Student Research Committee, Kashan University of Medical sciences, Kashan, Iran \\ "Corresponding author: Health Information Management Research Center, Kashan University of Medical Sciences, Kashan, Iran. Tel: +98-3155583188, Fax: +98-3155548883,
} Email: nabovati@kaums.ac.ir
}

Received 2018 January 22; Accepted 2018 August 02.

\begin{abstract}
Context: This systematic review was conducted to investigate the role of phones (telephone and mobile phone) in interventions designed to control obesity in children under age six and to determine the features and effects of these interventions.

Evidence Acquisition: A systematic search was conducted of the electronic databases (until November 2016). Randomized controlled trials that assessed the effects of phone-based interventions to control obesity in children under age six were included.

Results: Of the 1920 papers accessed, 38 were relevant based on title and abstract. After review of the full texts, five studies were deemed eligible for inclusion. The results showed that in two studies phone-based interventions succeeded in improving the children's weight and BMI while in three other studies they were not. Among the functionalities of a telephone and mobile phone (e.g. text messaging and smartphone applications), only phone calls were used to communicate with participants. Only one of the included studies had used the phone as its main intervention, in the other studies the phone was used as part of a multicomponent intervention. Most of the included studies used phone calls to encourage and remind the participants about their children's nutritional status and physical activity.

Conclusions: Although the numerous functions of phones can be used independently or in combination with other interventions for controlling obesity, so far, only the phone call function has been used for children under age six. Moreover, there is still no strong evidence on their positive effects on obesity control in children under age six.
\end{abstract}

Keywords: Pediatric Obesity, Overweight, Child, Mobile Phone, Systematic Review

\section{Context}

Children obesity is considered a serious public health problem that is not only a disease (1), but may also lead to social disabilities and diseases in adulthood in the long term $(2,3)$. The most common risk of childhood obesity is the development of maturity onset diabetes in young people. The highest prevalence of childhood obesity has been reported in developed countries $(4,5)$, although developing countries are also witnessing an increasing prevalence (6-9). A study conducted by the National Health and Nutrition Examination reported the prevalence of childhood obesity as approximately $12.4 \%$ (10).

Studies have shown that empowerment of parents and healthcare providers contribute significantly to the control of childhood obesity (11-13). The empowerment of parents and healthcare providers is performed through training (to raise awareness), increasing self-efficacy in childcare, and motivation for improving nutritional status. The psychological support of parents to change their usual methods of care and consultation in relation to their chil- dren's weight management is another helpful empowerment technique. Previous studies have shown that the empowerment of parents through information tools such as pamphlet, postcard, text message, phone call, and e-mail is effective in controlling children's obesity $(14,15)$.

Mobile health (mHealth) is a new area of healthcare that can be used for the empowerment of patients and their relatives in self-care (16). Telephones and mobile phones are one of the most-commonly-used tools in mHealth due to features such as real time data access, costeffectiveness, providing specific information to individuals, and reciprocal interaction between the participants (1). In addition to these features, mobile phones are also capable of connecting to the Internet and running different applications (17). Several studies have already shown that using mHealth helps improve self-care in patients with chronic diseases (18-20).

To date, several systematic reviews have been published on the effects of mHealth interventions on the control of obesity in various age groups but have failed to yield 
strong evidence. A systematic review conducted by Smith et al. on the effect of information technology (IT)-based interventions on the treatment of obesity in children aged two to 18 , showed little evidence on the positive effects of text messaging and phone calls on the children's body mass index (BMI) and other clinical outcomes (21). A systematic review by Quelly et al. on the effects of mobile applications on the behaviors and outcomes associated with obesity in children aged nine to 19 showed limited and contradictory evidence on the effects of mobile applications on the behaviors and outcomes associated with obesity control (22). Another systematic assessment of the effects of text messaging on weight management in all age groups showed very little evidence on the effect of text messaging on weight loss (23).

The aforementioned systematic reviews provide information on the effects of mHealth interventions on obesity control in different age groups, and one of the studies included studies that evaluated the effect of IT-based tools other than phones (such as electronic health records and telemedicine) (21). To the best of our knowledge, no systematic reviews have been undertaken to determine the role of telephone and mobile phone in obesity control interventions in children under age six, and the effects of these interventions on obesity control in this age group is still unknown. The present systematic review was conducted to investigate the role of a telephone and mobile phone in obesity control interventions in children under age six and to also determine the features and effects of these interventions.

\section{Evidence Acquisition}

\subsection{Data Sources and Search Strategies}

The electronic databases searched in this review were Medline (through PubMed), the Cochrane Central Register of Controlled Trials (Cochrane), and Scopus. The search was carried out of articles published from early 1990 to December 2016. The search strategy was designed using keywords and MeSH terms related to child (such as child, childhood, pediatric, children, kid, infant and minors), obesity (such as weight, over-weight, body mass index, BMI, obese, overweight and obesity), and phone (such as mHealth, phone, smartphone, mobile, telephone, and mobile application).

\subsection{Inclusion and Exclusion Criteria}

The inclusion criteria for the studies consisted of (1) being a randomized control trial, (2) using telephone or mobile phone as the main or part of the intervention, and (3) assessing weight or BMI outcomes in intervention group consisting of the parents or healthcare providers of children under age six. Only studies that had an intervention group along with a control group not receiving the telephone or mobile phone intervention were included. Studies whose target group consisted of one-month-old to sixyear-old children were included. The exclusion criteria for the study were as follows: being published in languages other than English, examining obesity caused by other diseases, using telephone or mobile phone only for data collection, and examining only participants' willingness to receive an intervention and the advantages and disadvantages of such interventions. Studies that had reported on the design, development, implementation, and validation of interventions including telephone and mobile phone or whose participants were only children over age six were excluded. Protocol studies, surveys, and conference proceedings were also excluded.

\subsection{Data Extraction}

The title, abstract, and full text of the identified articles were reviewed independently by two reviewers. Data were extracted from the included studies by the same reviewers using a structured form. Differences of opinion were resolved through discussion with the third reviewer. The data extracted from each study included the authors' names, publication year, country, participants' characteristics in the intervention and control groups, type and content of the intervention provided to the intervention and control groups, the role of telephone and mobile phone in the intervention, duration of the study, measured outcomes, and the effect of the intervention on the outcomes.

\subsection{Quality Assessment of the Studies}

The quality assessment of the studies was carried out by two reviewers using Cochrane Collaboration's assessment tool, which consists of six specific domains: (1) adequate random sequence generation, (2) allocation concealment, (3) blinding of participants and personnel, (4) blinding of outcome assessment, (5) incomplete outcome data, and (6) selective outcome reporting $(24,25)$.

\subsection{Data Analysis}

A narrative synthesis was performed according to the classification of the outcomes, the interventions, and their effects. For the synthesis based on the effects of the interventions on the outcomes, the studies were divided into a significantly positive effect group and a no effect group (26). The interventions were also classified according to the role of telephone and mobile phone in the intervention. The content provided through telephone and mobile phone in the intervention for each study were determined. 


\section{Results}

From the search on Medline (through PubMed), Scopus, and Cochrane databases, 1920 articles were retrieved as shown in Online Resource (Figure 1), 399 of which were duplicated and were thus excluded. Next, the full text of 38 articles that were deemed potentially relevant based on abstracts was reviewed. Eventually, five studies were included according to the inclusion and exclusion criteria. Three of the retrieved articles met most of the inclusion criteria, however, they were excluded from this study due to the fact that they had used a telephone or mobile phone in both the intervention and control groups and it was not possible to assess the effects of the phone-based intervention $(15,27$, 28).

The general characteristics of the included studies are shown in Table 1. Three studies were conducted in the United States of America (U.S.), one in Germany, and one in the Netherlands. All the included studies were published between 2014 and 2016.

The results of the quality assessment of the included studies are shown in Table 2. Two studies obtained a positive score in all the parameters evaluated (i.e. high quality) $(11,30)$ and two others obtained a positive score in half of the parameters (i.e. moderate quality) $(14,29)$. The one remaining study obtained a positive score in three of the parameters evaluated (i.e. low quality) (31).

Weight was an outcome only in two of the included studies while BMI (BMI and BMI Z-score) was an outcome in all five included studies (Table 3). The results showed statistically significant improvements in the intervention group compared with the control group in terms of weight in one high quality study (11) and in terms of BMI in two studies (one high quality study and one low quality study (11, 31). In contrast, no statistically significant differences were observed between the intervention and control group in terms of weight in one moderate quality study (14) and in terms of BMI in three studies (one high quality study and two moderate quality studies) $(14,29,30)$. Only one of the five included studies had used the phone as its main intervention (11); that study found improvements in both the weight and BMI outcomes and also obtained a positive rating in all the quality assessment parameters (a highquality study). In the four other studies, the phone was used as part of the multicomponent intervention $(14,29$ 31).

The results showed that, of all the functionalities of telephones and mobile phones, only the call function was used. None of the included studies had used the other functionalities of telephones and mobile phones, such as text messaging, video call, Internet access, social networks, and smartphone applications. Table 3 presents the content provided through phone calls in the included studies. The results showed that phone calls were used mostly to motivate and remind the participants to improve their children's physical activity and nutrition behaviors.

\section{Conclusions}

The studies included in this review assessed weight and BMI as outcomes and these outcomes improved in some of the included studies but remained unchanged in others. In all the included studies, only the call function of phones was used and the other functions of telephones and mobile phones such as text messaging, video calls, Internet access, social networks, and smartphone applications were not used in any of the studies. Phones were used as the main intervention in only one study and as part of the multicomponent intervention in the others. In most studies, phone calls were used mostly to motivate and remind the participants to improve their children's physical activity and nutrition behaviors.

The outcomes evaluated in the studies were children's weight and BMI. As a result of the phone intervention, these outcomes improved in some of the included studies but remained unchanged in others. The results of a similar systematic review showed that there is little evidence on the positive effects of text messaging interventions on weight loss in children and adults (23). Two other systematic reviews also showed that there is little evidence on the positive effects of mobile phone-based interventions (e.g. text messages and phone calls) for reducing weight and BMI $(21,22)$. The results of this review and similar ones show that, despite the ever-increasing use of telephones and mobile phones in healthcare, there is still limited evidence on the effects of the interventions based on these technologies on weight loss in different age groups.

Only one of the five studies included in this review used phones as the main intervention (11), and the others used phones as part of their multicomponent intervention. The poor use of the many functions of telephones and mobile phones as the main intervention may be due to the fact that researchers were more likely to believe in the effectiveness of traditional interventions, such as training and consultation in person, compared to technology-based interventions. On contrary to this, a recently published systematic review showed that technology-based interventions have a greater effect on the quality of life in patients with chronic obstructive pulmonary disease compared to traditional interventions (32). In the present review, only one study that used phones as its main intervention showed improvements in weight and BMI outcomes in its intervention group compared to the control; it should be noted 


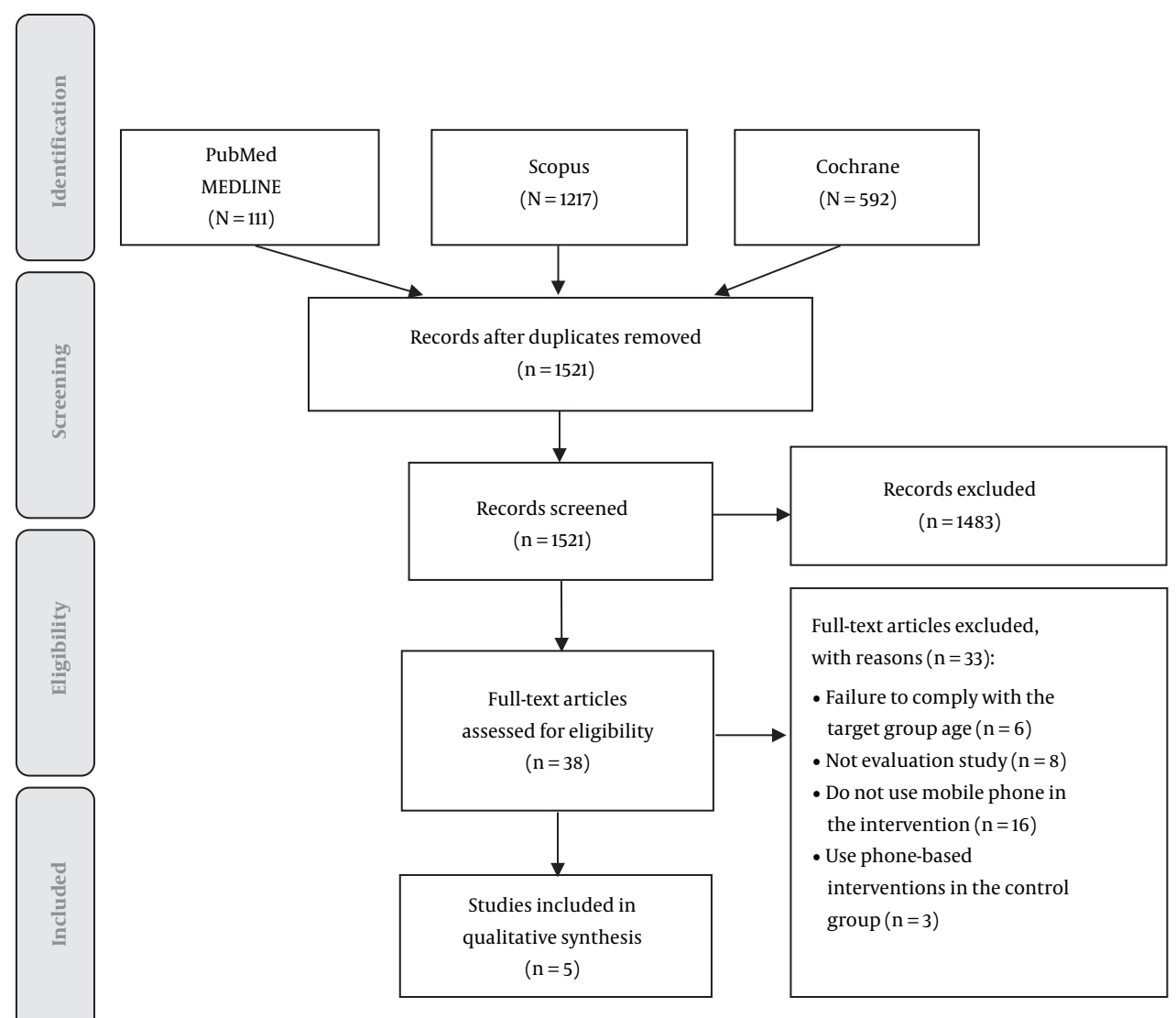

Figure 1. The study selection flow diagram

Table 2. The Quality of the Included Studies ${ }^{\mathrm{a}}$

\begin{tabular}{|c|c|c|c|c|c|c|c|c|c|}
\hline \multirow{2}{*}{ Reference } & \multirow{2}{*}{$\begin{array}{c}\text { Random } \\
\text { Sequence } \\
\text { Allocation }\end{array}$} & \multirow{2}{*}{$\begin{array}{c}\text { Allocation } \\
\text { Conceal- } \\
\text { ment }\end{array}$} & \multirow{2}{*}{ Blinding } & \multirow{2}{*}{$\begin{array}{c}\text { Incomplete } \\
\text { Outcomes } \\
\text { Data }\end{array}$} & \multirow{2}{*}{$\begin{array}{l}\text { Selective } \\
\text { Reporting }\end{array}$} & \multicolumn{3}{|c|}{ Other Bias } & \multirow{2}{*}{$\begin{array}{l}\text { Study } \\
\text { Quality }\end{array}$} \\
\hline & & & & & & Sample Size & $\begin{array}{l}\text { Intention } \\
\text { to Treat } \\
\text { Analysis }\end{array}$ & $\begin{array}{c}\text { Similarly, } \\
\text { Trained } \\
\text { Individuals }\end{array}$ & \\
\hline
\end{tabular}

\begin{tabular}{|c|c|c|c|c|c|c|c|c|c|c|}
\hline (30) & & $+^{*}$ & + & + & + & + & + & + & + & High \\
\hline (11) & & + & + & + & + & + & + & + & + & High \\
\hline$(14)$ & & $?^{*}$ & $?$ & $-*$ & - & + & + & + & + & Moderate \\
\hline (31) & & $?$ & $?$ & - & + & - & + & + & - & Low \\
\hline (29) & & $?$ & + & $?$ & - & + & + & + & - & Moderate \\
\hline \multicolumn{11}{|c|}{ Sum } \\
\hline & + & 2 & 3 & 2 & 4 & 4 & 5 & 5 & 3 & \\
\hline & - & & & 2 & 2 & 1 & & & 2 & \\
\hline & $?$ & 3 & 2 & 1 & & & & & & \\
\hline
\end{tabular}

a *(+) Low risk of bias, (?) unclear, (-) high risk of bias.

that in the methodological assessment this study was categorized as high quality (11).
In the reviewed studies, only the phone call function of phones was used in weight loss interventions for chil- 


\begin{tabular}{|c|c|c|c|c|}
\hline \multirow{2}{*}{ Study } & \multirow{2}{*}{ The Role of Phones } & \multirow{2}{*}{$\begin{array}{l}\text { Content Provided Through the Phone Call } \\
\text { Function }\end{array}$} & \multicolumn{2}{|c|}{ Outcome } \\
\hline & & & BMI & Weight \\
\hline (14) & $\begin{array}{l}\text { Phone as part of the } \\
\text { multicomponent } \\
\text { intervention }\end{array}$ & $\begin{array}{l}\text { Encouraging the participants to improve nutritional } \\
\text { status, Encouraging the participants to perform } \\
\text { physical activity, Responding to the questions }\end{array}$ & $\begin{array}{l}\text { Not statistically } \\
\text { significantly improved }\end{array}$ & $\begin{array}{l}\text { Not statistically } \\
\text { significantly improved }\end{array}$ \\
\hline (29) & $\begin{array}{l}\text { Phone as part of the } \\
\text { multicomponent } \\
\text { intervention }\end{array}$ & $\begin{array}{l}\text { Encouraging the participants to improve nutritional } \\
\text { status, identifying incompatibilities between the } \\
\text { actual and intended behaviors, teaching skills to } \\
\text { reduce incompatibilities between the actual and } \\
\text { intended behaviors }\end{array}$ & $\begin{array}{l}\text { Not statistically } \\
\text { significantly improved }\end{array}$ & - \\
\hline (30) & $\begin{array}{l}\text { Phone as part of the } \\
\text { multicomponent } \\
\text { intervention }\end{array}$ & $\begin{array}{l}\text { Supporting the implementation of strategies (e.g. } \\
\text { improved nutritional status and physical activity) at } \\
\text { home }\end{array}$ & $\begin{array}{l}\text { Not statistically } \\
\text { significantly improved }\end{array}$ & - \\
\hline (31) & $\begin{array}{l}\text { Phone as part of the } \\
\text { multicomponent } \\
\text { intervention }\end{array}$ & $\begin{array}{l}\text { Supporting behavioral changes at home (e.g. } \\
\text { improved nutritional status and physical activity) and } \\
\text { barriers upon exposure, assessing the mothers' } \\
\text { self-confidence in achieving goals (obesity } \\
\text { prevention), reinforcing positive behaviors, The } \\
\text { month review of self-care dates }\end{array}$ & $\begin{array}{l}\text { Statistically significantly } \\
\text { improved }\end{array}$ & - \\
\hline (11) & $\begin{array}{l}\text { Phone as the main } \\
\text { intervention }\end{array}$ & $\begin{array}{l}\text { Encouraging the participants to improve nutritional } \\
\text { status, providing counseling to the participants about } \\
\text { treatment methods related to comorbidities, leisure } \\
\text { time, psychological support, stress management and } \\
\text { self-care }\end{array}$ & $\begin{array}{l}\text { Statistically significantly } \\
\text { improved }\end{array}$ & $\begin{array}{l}\text { Statistically significantly } \\
\text { improved }\end{array}$ \\
\hline
\end{tabular}

dren under age six, which could be due to the simplicity, availability, and ability to transfer large amounts of information through phone calls compared to the other functions of telephones and mobile phones (e.g. text messaging). Phone calls, however, pose certain problems too, such as the need for both sides to simultaneously be online and the increased costs of employing a person to provide the intended information to the service recipient. The other functions of telephones and mobile phones do not have these defects and have been shown to be appropriate tools for implementing self-care programs $(33,34)$.

None of the studies included in this systematic review used the other functions of telephones and mobile phones in their interventions, which could be due to young children's inability to use these functions for their own selfcare or due to the fear of the potential adverse effects of mobile radiation on children's health, such as sleep disturbance, and stress and anxiety due to the use of mobile phones (35). The use of mobile phones may also reduce physical activity in children and cause even more obesity. Given the important role of parents and healthcare providers in taking care of children's health, the helpful functions of mobile phones can be used to empower these groups to control obesity in children under age six.

In the reviewed studies, phone calls were mostly used to encourage and remind the participants to improve the nutritional status and physical activity of their children at home. A similar systematic review showed that mobile technology has mostly been used in self-care for making recommendations to have proper nutrition and for obesity prevention programs (22). Woo et al. (2013) showed that the text messaging function of mobile phones has mostly been used in interventions to send messages alerting about weight and amount of food intake and encouraging the participants to perform physical activity (36). Smith et al. (2013) also showed that the most common use of health information technologies (electronic health records, telemedicine, and text messaging), in screening and treatment of child obesity, has been for the purpose of consultation about nutritional status and weight management (21). It can therefore be concluded that nutrition status and physical activity are key factors in children's weight loss and IT-based tools (such as interventions using phones) can be used to remind the importance of these factors to the service recipients.

The strengths of the present study were the inclusion of only randomized controlled trials to ensure the high quality of the studies and using the extensive search strategy that comprised all the keywords and MeSH terms related to obesity, child, and phone. However, the study has some limitations. The inclusion of English language papers and the exclusion of conference proceedings may have resulted in missing some possibly important papers published in other languages or presented in conferences. However, mostly the full text of conference proceedings could not be accessed. Moreover, the search for papers was carried out only in three databases (MEDLINE, Scopus, and Cochrane), therefore, some studies may have been missed. 
Considering that the results of the only study in which phone calls were used as the main intervention proved this intervention to effectively help with weight loss in children under age six, and since this study was of a high quality, healthcare providers dealing with children, pediatricians, and nutritionists are recommended to use such interventions to control obesity in children. Moreover, given that phone calls were found to be mostly used to encourage and remind parents about improving their children's nutritional status and physical activity, healthcare providers are recommended to also use these strategies.

Given that no studies were found on the effects of mobile phone functions such as text messaging, video calls, internet access, social networks, and smartphone applications on obesity control in children under age six, future studies are recommended to examine the effect of such interventions. Since all the studies conducted on this subject have examined children in developed countries, similar empirical studies should be carried out in developing countries.

Although the numerous functions of telephones and mobile phones can be used independently or in conjunction with other interventions for obesity control in different age groups, so far, only the phone call function has been used for the control of obesity in children under age six. Moreover, there is still no strong evidence on their positive effects on obesity control in children under age six.

\section{Footnote}

Ethics Approval: This study was approved by the Research Ethics Committee of Kashan University of Medical Sciences Research Council.

\section{References}

1. Turner T, Spruijt-Metz D, Wen CKF, Hingle MD. Prevention and treatment of pediatric obesity using mobile and wireless technologies: a systematic review. Pediatr Obesit. 2015;10(6):403-9.

2. Kolpa M, Jankowicz-Szymanska A, Jurkiewicz B. High-normal arterial blood pressure in children with excess body weight. Iran J Pediatr. 2016;26(4). e4677. doi: 10.5812/ijp.4677. [PubMed: 27713811]. [PubMed Central: PMC5045558].

3. Flodmark CE, Lissau I, Pietrobelli A. Child and adolescent obesity: why we need to fight!. Acta Paediatr Suppl. 2005;94(448):4-7. [PubMed: 16175800].

4. Ogden CL, Carroll MD, Kit BK, Flegal KM. Prevalence of childhood and adult obesity in the United States, 2011-2012. JAMA. 2014;311(8):80614. doi: 10.1001/jama.2014.732. [PubMed: 24570244]. [PubMed Central: PMC4770258]

5. Ogden CL, Carroll MD, Kit BK, Flegal KM. Prevalence of obesity and trends in body mass index among US children and adolescents, 19992010. JAMA. 2012;307(5):483-90. doi: 10.1001/jama.2012.40. [PubMed: 22253364].

6. Soheilipour F, Ghanbari Jolfaie A, Pourzahabi Z, Lotfi M, Moradi Lakeh M. The prevalence of obesity in school children of Zahedan-Iran; double burden of weight disorders. J Compr Pediatr. 2015;6(3). doi: 10.17795/compreped-26641.

7. Khodaee GH, Saeidi M. Increases of obesity and overweight in children: An alarm for parents and policymakers. Int J Pediatr. 2016;4(4):1591-601.

8. Gupta N, Shah P, Nayyar S, Misra A. Childhood obesity and the metabolic syndrome in developing countries. Indian JPediatr. 2013;80 Suppl 1:S28-37. doi: 10.1007/s12098-012-0923-5. [PubMed: 23334584].

9. Pienaar AE. Prevalence of overweight and obesity among primary school children in a developing country: NW-CHILD longitudinal data of 6-9-yr-old children in South Africa. BMC Obes. 2015;2:2. doi: 10.1186/s40608-014-0030-4. [PubMed: 26217517]. [PubMed Central: PMC4511440].

10. Centers for Disease Control and Prevention. Childhood overweight and obesity. 2010. Available from: http://www.cdc.gov/obesity/ childhood/index.html.

11. Markert J, Herget S, Petroff D, Gausche R, Grimm A, Kiess W, et al. Telephone-based adiposity prevention for families with overweight children (T.A.F.F.-Study): one year outcome of a randomized, controlled trial. Int J Environ Res Public Health. 2014;11(10):10327-44. doi: 10.3390/ijerph111010327. [PubMed: 25286167]. [PubMed Central: PMC4210981].

12. Irby MB, Boles KA, Jordan C, Skelton JA. TeleFIT: adapting a multidisciplinary, tertiary-care pediatric obesity clinic to rural populations. Telemed J E Health. 2012;18(3):247-9. doi: 10.1089/tmj.2011.0117. [PubMed: 22356527]. [PubMed Central: PMC3317399].

13. Okely AD, Collins CE, Morgan PJ, Jones RA, Warren JM, Cliff DP, et al. Multi-site randomized controlled trial of a child-centered physical activity program, a parent-centered dietary-modification program, or both in overweight children: the HIKCUPS study. J Pediatr. 2010;157(3):388-94. 394 e1. doi: 10.1016/j.jpeds.2010.03.028. [PubMed: 20447648]

14. Schroeder N, Rushovich B, Bartlett E, Sharma S, Gittelsohn J, Caballero B. Early obesity prevention: a randomized trial of a practice-based intervention in 0-24-month infants. Hindawi Pub Corp Obesit. 2015.

15. Sherwood NE, JaKa MM, Crain AL, Martinson BC, Hayes MG, Anderson JD. Pediatric primary care-based obesity prevention for parents of preschool children: a pilot study. Child Obes. 2015;11(6):674-82. doi: 10.1089/chi.2015.0009. [PubMed: 26478951]. [PubMed Central: PMC4677530].

16. Nacinovich M. Defining mHealth. J Commun Healthcare. 2013;4(1):1-3. doi: 10.1179/175380611x12950033990296.

17. Kumar S, Nilsen WJ, Abernethy A, Atienza A, Patrick K, Pavel $M$, et al. Mobile health technology evaluation: the mHealth evidence workshop. Am J Prev Med. 2013;45(2):228-36. doi: 10.1016/j.amepre.2013.03.017. [PubMed: 23867031]. [PubMed Central: PMC3803146].

18. Beratarrechea A, Lee AG, Willner JM, Jahangir E, Ciapponi A, Rubinstein A. The impact of mobile health interventions on chronic disease outcomes in developing countries: a systematic review. Telemed J E Health. 2014;20(1):75-82. doi: 10.1089/tmj.2012.0328. [PubMed: 24205809]. [PubMed Central: PMC3880111].

19. Cafazzo JA, Casselman M, Hamming N, Katzman DK, Palmert MR Design of an mHealth app for the self-management of adolescent type 1 diabetes: a pilot study. J Med Internet Res. 2012;14(3). e70. doi: 10.2196/jmir.2058. [PubMed: 22564332]. [PubMed Central: PMC3799540].

20. El-Gayar O, Timsina P, Nawar N, Eid W. Mobile applications for diabetes self-management: status and potential. J Diabetes Sci Technol. 2013;7(1):247-62. doi: 10.1177/193229681300700130. [PubMed: 23439183]. [PubMed Central: PMC3692239].

21. Smith AJ, Skow A, Bodurtha J, Kinra S. Health information technology in screening and treatment of child obesity: a systematic review. American Academ Pediatr. 2012. doi: 10.1098/rstb.2011.0173. [PubMed: 22144393]. [PubMed Central: PMC3223799]. 
22. Quelly SB, Norris AE, DiPietro JL. Impact of mobile apps to combat obesity in children and adolescents: A systematic literature review.J Spec Pediatr Nurs. 2016;21(1):5-17. doi:10.1111/jspn.12134. [PubMed: 26494019].

23. Siopis G, Chey T, Allman-Farinelli M. A systematic review and metaanalysis of interventions for weight management using text messaging. British Dietetic Associat Ltd. 2014;2:1-15.

24. Chess LE, Gagnier J. Risk of bias of randomized controlled trials published in orthopaedic journals. BMC Med Res Methodol. 2013;13:76 doi: 10.1186/1471-2288-13-76. [PubMed: 23758875]. [PubMed Central PMC3724580].

25. Higgins JP, Green S. Cochrane handbook for systematic reviews of interventions. Johns Wiley and sons; 2011. $4 \mathrm{p}$.

26. Nabovati E, Vakili-Arki H, Taherzadeh Z, Saberi M, Medlock S, AbuHanna A. Information technology-based interventions to improve drug-drug interaction outcomes: a systematic review on features and effects. Med Sys. 2017;41(1):12.

27. Taveras EM, McDonald J, O'Brien A, Haines J, Sherry B, Bottino CJ, et al. Healthy habits, happy homes: methods and baseline data of a randomized controlled trial to improve household routines for obesity prevention. Prev Med. 2012;55(5):418-26. doi: 10.1016/j.ypmed.2012.08.016. [PubMed: 22960162].

28. Sherwood NE, Levy RL, Langer SL, Senso MM, Crain AL, Hayes MG, et al. Healthy homes/healthy kids: a randomized trial of a pediatric primary care-based obesity prevention intervention for at-risk 5-10 year olds. Contemp Clin Trials. 2013;36(1):228-43. doi: 10.1016/j.cct.2013.06.017. [PubMed: 23816490]. [PubMed Central: PMC4004341].

29. Rifas-Shiman SL, Taveras EM, Gortmaker SL, Hohman KH, Horan CM, Kleinman KP. Two-year follow-up of a primary care-based interven- tion to prevent and manage childhood obesity: the High Five for Kids study. Pediatr Obesit. 2016;12(3):24-7.

30. Gerards SM, Dagnelie PC, Gubbels JS, van Buuren S, Hamers FJ, Jansen MW, et al. The effectiveness of lifestyle triple P in the Netherlands: a randomized controlled trial. PLoS One. 2015;10(4). e0122240. doi: 10.1371/journal.pone.0122240. [PubMed: 25849523]. [PubMed Central: PMC4388496].

31. Cloutier MM, Wiley J, Huedo-Medina T, Ohannessian CM, Grant A, Hernandez D, et al. Outcomes from a Pediatric Primary Care Weight Management Program: Steps to Growing Up Healthy. J Pediatr. 2015;167(2):372-7 e1. doi: 10.1016/j.jpeds.2015.05.028. [PubMed: 26073106].

32. McCabe C, McCann M, Brady AM. Computer and mobile technology interventions for self-management in chronic obstructive pulmonary disease. Cochrane Database Syst Rev. 2017. doi: 10.1002/14651858.CD011425.pub2.

33. Patrick K, Raab F, Adams MA, Dillon L, Zabinski M, Rock CL. A Text Message-Based Intervention for Weight Loss: Randomized Controlled Trial. Med Inet Res. 2009;1(11).

34. Norman GJ, Zabinski MF, Adams MA, Rosenberg DE, Yaroch AL, Atienza AA. A review of eHealth interventions for physical activity and dietary behavior change. Am J Prev Med. 2007;33(4):336-45. doi: 10.1016/j.amepre.2007.05.007. [PubMed: 17888860]. [PubMed Central: PMC2180189].

35. Naeem Z. Health risks associated with mobile phones use. Health Scie Qassim Univ. 2014;8(4):1-2.

36. Woo J, Chen J, Ghanavati V, Lam R, Mundy N, Li LC. Effectiveness of cellular phone-based interventions for weight loss in overweight and obese adults: a systematic review. Orthopedic Muscular Syst Current Res. 2013;3(141). 


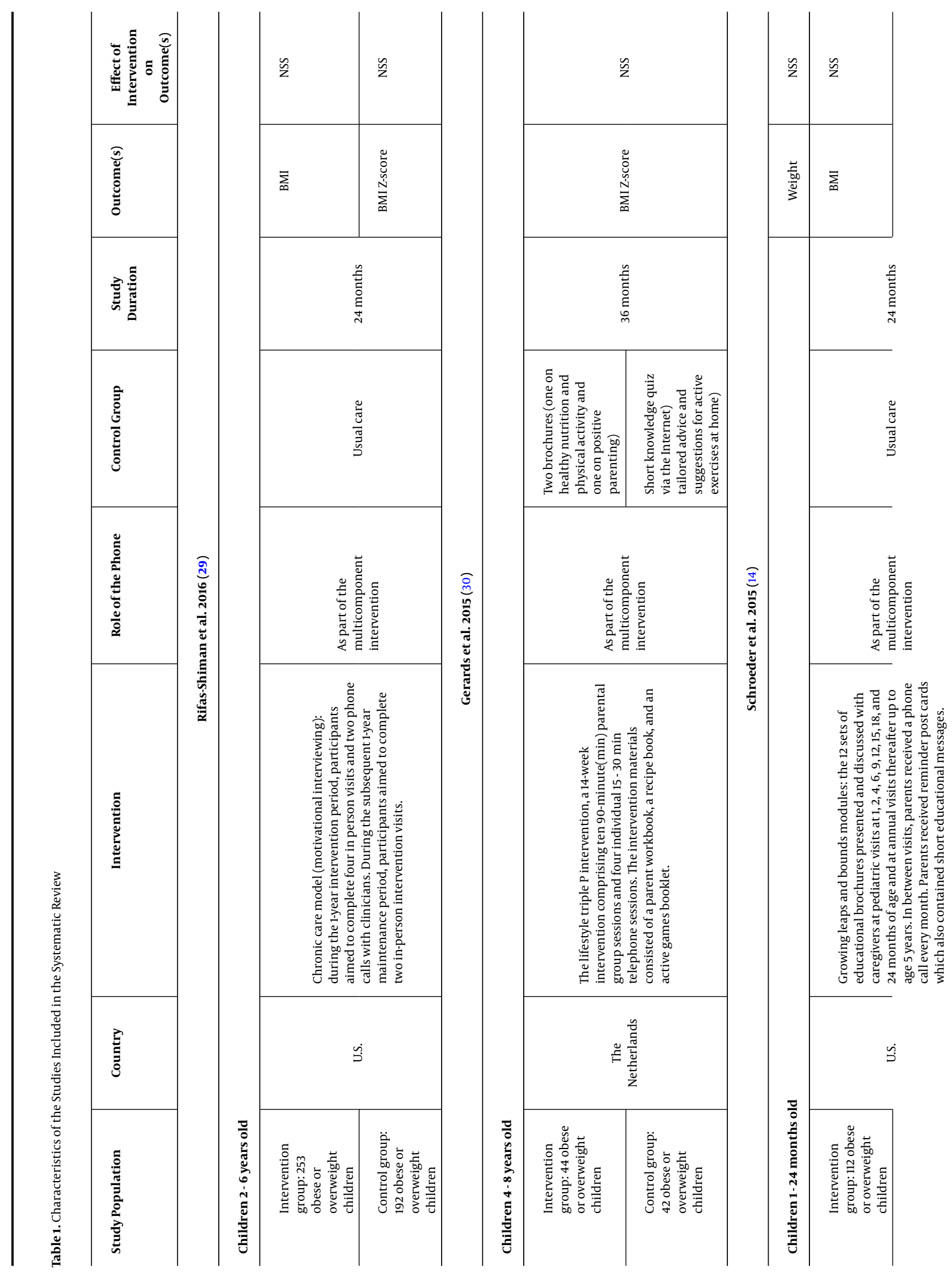




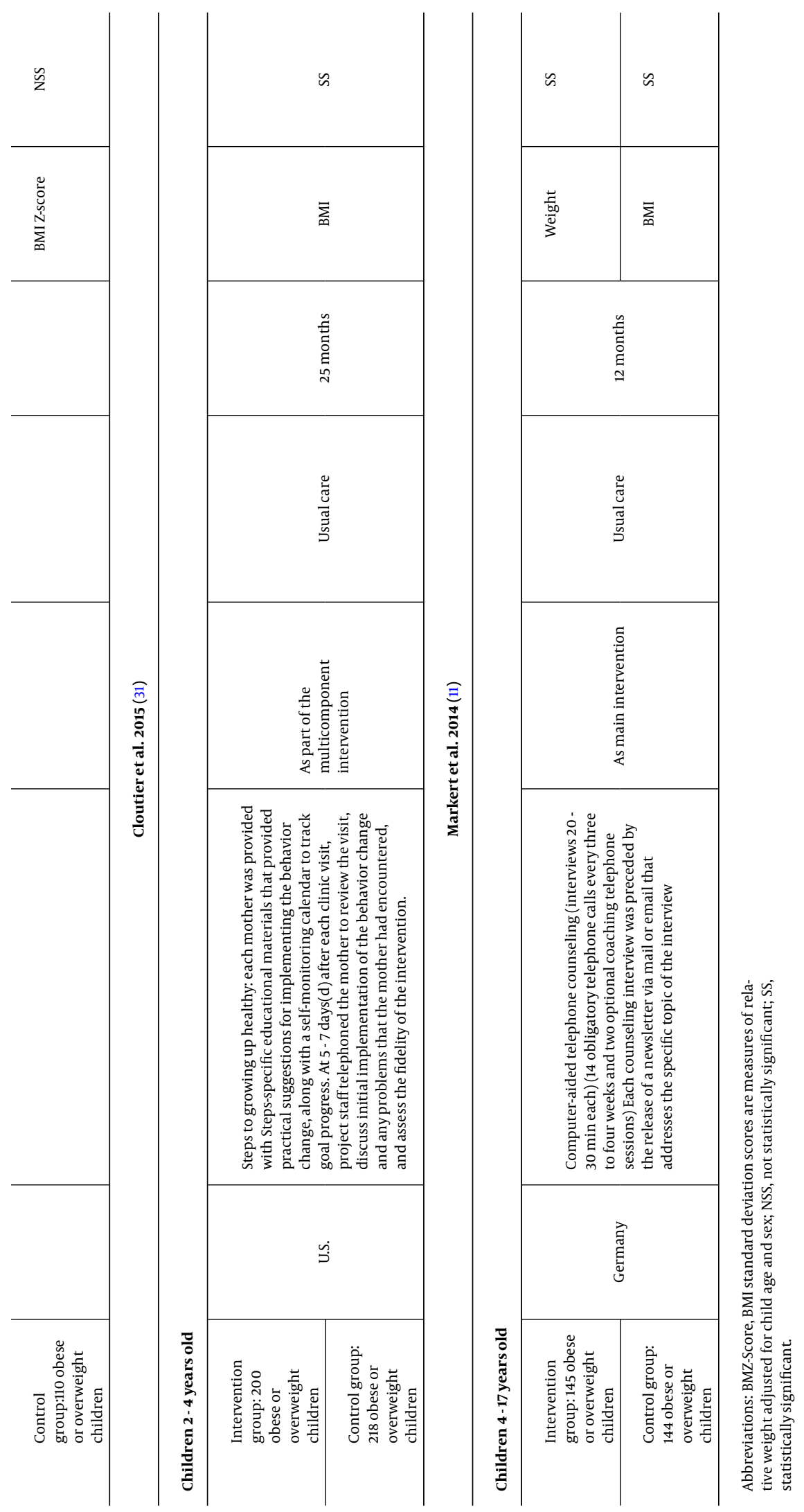

